Federal Reserve Bank of Dallas

Globalization and Monetary Policy Institute

Working Paper No. 50

http://www.dallasfed.org/assets/documents/institute/wpapers/2010/0050.pdf

\title{
Measuring Business Cycles by Saving for a Rainy Day*
}

\author{
Mario J. Crucini \\ Vanderbilt University and NBER \\ Mototsugu Shintani \\ Vanderbilt University
}

June 2010

\begin{abstract}
We propose a simple saving-based measure of the cyclical component in GDP. The measure is motivated by the prediction that the representative consumer changes savings in response to temporary deviations of income from its stochastic trend, while satisfying a present-value budget constraint. To evaluate our procedure, we employ the bivariate error correction model of Cochrane (1994) to the member countries of the G-7 and Australia. Our estimates reveal, that to a close approximation, the stochastic trend component of GDP is consumption and the transitory component is the error correction term, which justifies the use of our saving-based measure.
\end{abstract}

JEL codes: E3, E32, F41

\footnotetext{
Mario Crucini, Department of Economics, Vanderbilt University, VU Station B \#351819, 2301 Vanderbilt Place, Nashville, TN 37235-1819. 615-322-7357. mario.j.crucini@vanderbilt.edu. Mototsugu Shintani, Department of Economics, Vanderbilt University, VU Station B \#351819, 2301 Vanderbilt Place, Nashville, TN 37235-1819. 615-322-2196. mototsugu.shintani@vanderbilt.edu. The authors thank John Cochrane, Reuven Glick, Robert King and Kenneth Rogoff for helpful detailed comments and suggestions on earlier version of the paper. We gratefully acknowledge the financial support of the National Science Foundation. The views in this paper are those of the authors and do not necessarily reflect the views of the Federal Reserve Bank of Dallas or the Federal Reserve System.
} 


\section{Introduction}

Applied macroeconomic analysis inevitably begins with a decomposition of aggregate output into a business cycle component and a growth component. Most researchers rely on statistical filters to achieve this decomposition and rationalize a particular parametric choice of the filter (or computer algorithm) based upon preconceptions of what a business cycle should look like. A common view of what a business cycle component should look like is that it replicate the National Bureau of Economic Research Business Cycle Dating Committee's choices of business cycle peaks and troughs. While we do not deny the utility of this approach, there is a certain arbitrariness in the metric used to decide if a particular business cycle is too short or too long, particularly when the broader objective of the decomposition is to speak to both the growth and business cycle literatures. One alternative approach is to fully specify and estimate a particular DSGE model. A second alternative is to rely on actual consumption responses to infer a representative agent's view of trend and cyclical components, imposing minimal economic restrictions common to a wide class of models. While the DSGE approach mitigates the obvious 'measurement without theory' concern of critics of business cycle filters, it is subject to the issue of model misspecification which could make the decomposition into trend and cycle totally invalid. Consequently, we opt for the latter course of action.

In this paper, we conduct trend-cycle decompositions of aggregate output using one of the most basic conditions imposed in almost all macroeconomic models - the representative consumer's long-run budget constraint. In the presence of a stochastic trend, the long-run budget constraint requires cointegration of consumption and total income. However, consumption is less volatile and contains better information about the long-run trend than does income alone. This motivates a multivariate approach to trend-cycle decompositions using consumption as a proxy for the trend component, which implies that the cyclical component of output is essentially equal to national saving. Unlike other economic based decompositions available in the literature, our procedure is extremely simple to apply, embodies an 
economic restriction found in virtually every macroeconomic model and is unlikely to involve misspecification.

The idea of using consumption as a covariate in trend-cycle decompositions of output is not new. Motivated by the permanent income model, Cochrane (1994) considers a bivariate error correction model (ECM) of GNP and consumption with a log consumption/GNP ratio as the error correction term to capture the cointegration of these two economic variables. He then conducts a multivariate Beveridge-Nelson (BN) decomposition using an ECM estimated using U.S. quarterly data. Cochrane's ECM/BN approach is extended to include asset wealth as an additional covariate by Lettau and Ludvigson (2004). ${ }^{1}$ Instead of using the ECM/BN approach, Morley (2007) considers a bivariate unobserved components (UC) model of GDP and consumption while imposing a cointegrating restriction for the purpose of estimating the stochastic trend component of the output. ${ }^{2}$ In these studies, the short-run dynamics of the model are estimated parametrically. In contrast, our saving-based measure of business cycles does not require a parametric specification of short-run business cycle dynamics.

The nonparametric nature of our approach has similarities to the Hodrick-Prescott (HP) filter, the most common approach to business cycle decompositions presently in use. When using consumption as a proxy for the stochastic trend, as emphasized in this paper, it is natural to smooth out the transitory component from the raw consumption series. One of our proposed saving measures applies the HP filter to obtain a smoothed consumption series before subtracting it from output to estimate the cyclical component. This measure may be viewed as a multivariate HP filtering method which imposes a long-run cointegrating relationship between consumption and output. The estimated cycle based on this procedure, however, turns out to differ greatly from univariate HP filter applied to output alone, as done in the business cycle literature.

Since our approach is most closely related to Cochrane's study, we revisit his ECM/BN

\footnotetext{
${ }^{1}$ While not in ECM format, Rotemberg and Woodford (1996) and Ravn (1997) also use the BN decomposition applied to a three variable system of log output, log consumption/output ratio and log hours worked.

${ }^{2}$ For a comparison of UC models and BN decompositions, see Morley, Nelson and Zivot (2003).
} 
method in detail both theoretically and empirically. The results of the ECM/BN decomposition serve as a benchmark to evaluate the performance of our simplified measure. Importantly, our saving-based measure nests the ECM/BN cycle with the cointegrating restriction in many cases. As noted by Cochrane (1994), in the special case in which consumption is an exact random walk: "the Beveridge-Nelson trend would exactly equal consumption less the mean log GNP/consumption ratio" (page 252). In such a case, the saving measure would work without the need to smooth consumption at all. Even in the presence of transitory variation in consumption, we show that the ECM/BN estimate of the business cycle is extremely well approximated by saving when raw consumption is replaced by a moving average of current and past consumption.

Cochrane's analysis of U.S. output and consumption is extended to include the G-7 plus Australia. To evaluate the plausibility of the estimated model, impulse responses and variance decomposition analysis of permanent and transitory shocks in the ECM are reported. The estimated impulse response functions are found to be qualitatively consistent with the simple permanent income model and even better approximations to the predictions of the one-sector DSGE workhorse model of macroeconomics. To identify each shock, Cochrane's ECM is slightly modified by imposing a zero restriction on the error correction term in consumption equation. As it turns out, a simple saving-based measure tracks the more elaborate estimated ECM/BN cycle very closely in every country. Surprisingly, the role of short-run dynamics in the ECMs are typically negligible. Simply put: a linearly detrended savings (rate) alone captures most of the transitory variation in output. Thus Cochrane's conjecture on the usefulness of consumption as a proxy for the BN trend seems valid not only for the U.S. but also for other industrialized countries. ${ }^{3}$

Our approach to trend-cycle decompositions is simple and gives a different cyclical component than existing approaches. The implications of this are discussed in a later section of the paper where we focus on the international business cycle comovement puzzle and the

\footnotetext{
${ }^{3}$ Work in progress demonstrates the applicability of this decomposition to 160 or so countries over the last 30 years.
} 
Great Moderation debate.

Throughout the paper, we use the notation $y_{t}=100 \times \ln Y_{t}$ and $c_{t}=100 \times \ln C_{t}$, where $Y_{t}$ is Gross Domestic Product and $C_{t}$ is the aggregate private consumption.

\section{The trend-cycle decomposition of GDP}

\subsection{A saving-based measure of the business cycle}

Consider the additive (in logs) trend-cycle decomposition of output $y_{t}$,

$$
y_{t}=y_{t}^{g}+y_{t}^{c},
$$

where $y_{t}^{g}$ is the 'growth' or 'trend' component and $y_{t}^{c}$ is the 'cyclical' or 'transitory' component. Instead of relying on researcher's preconceptions about business cycle frequencies, the idea is to obtain the cyclical component such that a representative agent would view it as a transitory deviation from the stochastic trend in output. One approach to achieving such a decomposition is to specify a representative agent model and estimate its deep parameters. Here, instead, the focus is on the present value budget constraint faced by the representative consumer. The long-run budget constraint identity implies that income and consumption share a common long-run trend. In other words, income and consumption are cotrending. Since almost every modern macroeconomic model embodies this sensible economic restriction, it is useful to impose it at the outset.

Simple characterizations of the permanent income model rely on restrictive assumptions such as a constant interest rate, exogenous endowment and quadratic utility. However, as an approximation, it is often a convenient benchmark model to understand the core implications of more general models. For example, under the assumption of a stochastic trend in income, a closed form solution from the rational expectation-permanent income model implies that consumption and income are cointegrated. Campbell (1987) provides supporting evidence for this prediction using the U.S. quarterly data. ${ }^{4}$ He further points out that the same closed

\footnotetext{
${ }^{4}$ This implication of cointegration is also examined using select international data by Campbell and Clarida (1987) for Canada and U.K., MacDonald and Kearney (1990) for Australia, and Shintani (1994) for
} 
form solution of the permanent income model implies that saving, defined as the difference between total disposable income and consumption, should be high when income is expected to fall. Essentially this is a logarithmic version of the familiar 'saving for a rainy day' implication of the permanent income model found in Campbell and Deaton (1989).

If aggregate output is used in place of total disposable income, the simple permanent income model suggests that the common stochastic trend is permanent income, $y_{t}^{g}=c_{t}$, and the transitory component is savings, $y_{t}^{c}=s_{t}=y_{t}-c_{t}$. In practice, consumption does not necessarily follow a pure random walk process as suggested by the model. The point, however, is that consumption is less volatile than output and therefore contains better information about the trend as a result of thoughtful consumption decisions made by rational consumers. Thus, consumption is expected to be a good proxy for the trend after removing its transitory component, sometimes referred to as 'transitory consumption.' This motivates the following simple measure of the cyclical component in GDP based on a modified aggregate saving:

$$
y_{t}^{c}=y_{t}-\bar{c}_{t}^{g}-\alpha-\beta t
$$

where $\bar{c}_{t}^{g}$ is the estimated trend based on smoothed consumption. If $\bar{c}_{t}^{g}=c_{t}$ and if there is no deterministic trend component ( $\alpha=0$ and $\beta=0$ ), the measure reduces to just aggregate saving itself, $s_{t}=y_{t}-c_{t}$. For the consumption trend, one may simply use the moving average of lagged consumption as, $\bar{c}_{t}^{g}=(1 / M) \sum_{j=0}^{M-1} c_{t-j}$ where $M$ is the moving average length.

Typically, the HP filter is applied to output and consumption by minimizing

$$
\sum_{t=1}^{T}\left(y_{t}^{c}\right)^{2}+\lambda \sum_{t=1}^{T}\left[\left(y_{t+1}^{g}-y_{t}^{g}\right)-\left(y_{t}^{g}-y_{t-1}^{g}\right)\right]^{2} .
$$

and

$$
\sum_{t=1}^{T}\left(c_{t}^{c}\right)^{2}+\lambda \sum_{t=1}^{T}\left[\left(c_{t+1}^{g}-c_{t}^{g}\right)-\left(c_{t}^{g}-c_{t-1}^{g}\right)\right]^{2}
$$

separately, where $\lambda$ is a smoothing parameter chosen by the researcher and $z_{t}^{c}=z_{t}-z_{t}^{g}$, $z=y, c$. Obviously, by separately filtering income and consumption, their is no guarantee that income and consumption obey a cointegrating restriction.

Japan. 
One option is to employ a constrained multivariate HP filter which minimizes

$$
\begin{aligned}
& \sum_{t=1}^{T}\left(y_{t}^{c}\right)^{2}+\lambda \sum_{t=1}^{T}\left[\left(y_{t+1}^{g}-y_{t}^{g}\right)-\left(y_{t}^{g}-y_{t-1}^{g}\right)\right]^{2} \\
& +\omega_{1}\left\{\sum_{t=1}^{T}\left(c_{t}^{c}\right)^{2}+\lambda \sum_{t=1}^{T}\left[\left(c_{t+1}^{g}-c_{t}^{g}\right)-\left(c_{t}^{g}-c_{t-1}^{g}\right)\right]^{2}\right\} \\
& +\omega_{2} \sum_{t=1}^{T}\left(c_{t}^{g}-y_{t}^{g}\right)^{2}
\end{aligned}
$$

where $\omega_{1}$ and $\omega_{2}$ are weights controlling the relative importance of the two variables as well as the long-run restriction involving the growth components of consumption and income. The approach developed in this paper does not require the researcher to choose $\omega_{1}$ and $\omega_{2}$. The HP trend component of consumption which minimizes (2.3), denoted, $c_{t}^{g}$, is used as the measure of smoothed consumption. Thus simply setting $\bar{c}_{t}^{g}=c_{t}^{g}$ and substituting this into (2.1) defines the HP-version of our saving-based business cycle measure.

If $y_{t}$ and $c_{t}$ are cointegrated, $y_{t}$ and $\bar{c}_{t}^{g}$ are also cointegrated. In the presence of a linear deterministic trend, the cointegrating vector that eliminates a common stochastic trend may or may not eliminate a common deterministic trend at the same time. Using the terminology of Ogaki and Park (1997), two variables are deterministically cointegrated if the cointegrating

relationship also eliminates the deterministic trend. The long-run budget constraint is more closely related to this notion of deterministic cointegration, suggesting $\beta=0$ in the definition of the saving-based measure of the cycle. However, leaving the room for the possibility of $\beta \neq 0$ may be useful in some cases as it can proxy for missing additional covariates (e.g., an asset variable), a the gradual shift in the preference for the precautionary saving, or the presence of measurement errors. In applications, the residual from the regression of $y_{t}-\bar{c}_{t}^{g}$ on a linear trend allows for such possibilities.

\subsection{A bivariate Beveridge-Nelson decomposition of Cochrane's (1994) error cor- rection model}

Cochrane (1994) extracts the information on the trend in GNP from consumption using a bivariate error correction model (ECM) of GNP and consumption combined with a multivariate Beveridge-Nelson (BN) decomposition. 
The specification of the ECM employed here is,

$$
\begin{aligned}
\Delta c_{t}= & \alpha_{c 1}+\alpha_{c 2} t+\beta_{c 1} \Delta c_{t-1}+\beta_{c 2} \Delta c_{t-2}+\beta_{c 3} \Delta y_{t-1}+\beta_{c 4} \Delta y_{t-2}+\varepsilon_{t}^{c} \\
\Delta y_{t}= & \alpha_{y 1}+\alpha_{y 2} t+\gamma_{y}\left(c_{t-1}-y_{t-1}\right) \\
& +\beta_{y 1} \Delta c_{t-1}+\beta_{y 2} \Delta c_{t-2}+\beta_{y 3} \Delta y_{t-1}+\beta_{y 4} \Delta y_{t-2}+\varepsilon_{t}^{y}
\end{aligned}
$$

where $\varepsilon_{t}^{c}$ and $\varepsilon_{t}^{y}$ are non-orthogonalized shocks. The fixed lag length of 2 follows Cochrane. Note that equation (2.5) involves two modifications of Cochrane's original ECM: including time trends in both equations and omitting the error correction term, $c_{t-1}-y_{t-1}$, from the consumption growth equation. The trend terms are included to reflect the elimination of any deterministic trend from our saving-based cyclical component and the absence of error correction term in consumption growth equation is related to shock identification as explained below.

Consider the role of the loading coefficient $\gamma_{y}$. A characteristic equation of a cointegrated bivariate system should have one unit root and the other root outside the unit circle. Thus, in the absence of an error correction term in (2.5), cointegration of consumption and income requires $\gamma_{y} \in(0,2)$ in $(2.6)$. For this reason, the estimate of $\gamma_{y}$ has a direct implication for the long-run budget constraint. If $\gamma_{y}=0$, both consumption and income are difference stationary and they are not cointegrated. ${ }^{5}$ Since the t-statistic follows a nonstandard distribution under the null hypothesis $\gamma_{y}=0$, Cochrane employs a bootstrap method to claim that the coefficient is significantly different from zero in his analysis. As long as the cointegrating restriction $\gamma_{y} \in(0,2)$ is satisfied, however, the ordinary least squares (OLS) estimator remains asymptotically normal.

To calculate the impulse response functions of this ECM, Cochrane employs the conventional recursive orthogonalization of shocks with the order consumption and then income. The identified shocks can be interpreted as the permanent and transitory shocks since the orthogonalized shock in (2.6) which has zero (contemporaneous) impact on consumption cannot be a permanent shock, according to the permanent income model. To be more specific,

\footnotetext{
${ }^{5}$ If $\gamma_{y}<0$ or $\gamma_{y}>2$, the system is an explosive process.
} 
the permanent shock, denoted by $\nu_{t}^{P}$, and the transitory shock, denoted by $\nu_{t}^{T}$, are identified as

$$
\left[\begin{array}{c}
\nu_{t}^{P} \\
\nu_{t}^{T}
\end{array}\right]=R^{-1}\left[\begin{array}{c}
\varepsilon_{t}^{c} \\
\varepsilon_{t}^{y}
\end{array}\right]
$$

where $R$ is the lower triangular matrix which satisfies $R R^{\prime}=E\left(\epsilon_{t} \epsilon_{t}^{\prime}\right)=\Sigma$ and $E\left(\nu_{t} \nu_{t}^{\prime}\right)=I$ where $\epsilon_{t}^{\prime}=\left[\begin{array}{ll}\varepsilon_{t}^{c} & \varepsilon_{t}^{y}\end{array}\right]$ and $\nu_{t}^{\prime}=\left[\begin{array}{ll}\nu_{t}^{P} & \nu_{t}^{T}\end{array}\right]$. In addition to the permanent response to $\nu_{t}^{P}$, the presence of cointegration (i.e., the error correction term) restricts the impulse responses of consumption and income to converge to a common level in the long-run in response to either shock, consistent with the long-run budget constraint. ${ }^{6}$

To get a sense of how the estimated impulse responses of the ECM compare to those arising from a workhorse macroeconomic model, Figure 1 shows theoretical impulse responses of income and consumption to permanent and persistent productivity shocks using the onesector neoclassical model calibrated to the U.S. economy by King, Plosser and Rebelo (1988). The permanent shock scenario is the impulse response of the model following a $1 \%$ innovation to productivity under the assumption productivity follows a pure random walk. The transitory shock scenario assumes a first-order autoregressive process for productivity with persistence set at 0.9. By comparing the top panel of Figure 1 of Cochrane (1994, p. 245) with our Figure 1, we see that Cochrane's estimated impulse responses of GNP and consumption to permanent (consumption) and transitory (GNP) shocks match up surprisingly well with those of the calibrated model.

One notable difference is a small permanent effect of what Cochrane identifies as a transitory (GNP) shock, whereas the persistent, but transitory productivity shock has no long-run impact of either consumption or output in our estimated system or in the basic neoclassical model. The difference is due to the fact that Cochrane includes the error correction term in both equations of the ECM. Let $\gamma_{c}$ be the parameter on the error-correction-term in consumption growth equation in Cochrane's specification. Then, the long-run responses to

\footnotetext{
${ }^{6}$ See King, Plosser, Stock and Watson (1991) on this point.
} 
the identified transitory shock are:

$$
\lim _{h \rightarrow \infty} \frac{\partial E_{t}\left(y_{t+h}\right)}{\partial \nu_{t}^{T}}=\lim _{h \rightarrow \infty} \frac{\partial E_{t}\left(c_{t+h}\right)}{\partial \nu_{t}^{T}}=\frac{-\gamma_{c}}{\gamma_{y}-\gamma_{c}}
$$

From Table 1 of Cochrane (1994, p. 243) $\widehat{\gamma}_{c}=-0.02$ and $\widehat{\gamma}_{y}=0.08$, and this formula gives a long-run impulse response of $0.2(=0.02 / 0.1)$ consistent with Figure 1 of Cochrane's paper. As long as $\gamma_{y} \neq 0$, the transitory shock, $\nu_{t}^{T}$, identified by a recursive scheme has zero long-run effect if and only if $\gamma_{c}=0$, as imposed in equation 2.4. An alternative is to directly impose a zero long-run impulse response assumption as Blanchard and Quah (1989) do. However, a simple application of Blanchard-Quah method cannot incorporate the contemporaneous impact of the permanent shock implied by the permanent income model. ${ }^{7}$

For this reason, the zero restriction on the loading coefficient $\gamma_{c}$ in the consumption growth equation is imposed when estimating the ECM in what follows. Due to the fact that the two equations no longer have common regressors, OLS becomes inefficient since the equivalence of OLS and generalized least squares (GLS) no longer holds. To achieve efficiency, we employ a restricted multivariate GLS method. The GLS estimator is asymptotically normal as long as the cointegrating restriction $\gamma_{y} \in(0,2)$ is satisfied as shown in the Statistical Appendix.

Having established the appropriateness of the ECM and the estimation method, the remaining technical detail is the $\mathrm{BN}$ decomposition in the ECM context. The multivariate BN decomposition in a cointegrated system was first proposed by Stock and Watson (1988) and has been used in many applied studies, including Cochrane (1994), Evans and Reichlin (1994), and Lettau and Ludvigson (2004). As in the case of a univariate BN decomposition, both the trend and cycle components are generated from a common vector error component. The trend component follows a (multivariate) random walk process, while the cyclical component is serially correlated. This feature contrasts to an alternative decomposition based on the ECM, often referred to as Granger-Gonzalo decomposition (Gonzalo and Granger,

\footnotetext{
${ }^{7}$ Cochrane also argues that the conventional identification scheme has an advantage over Blanchard and Quah scheme as the former does not require an estimate of the spectral density at frequency zero.
} 
1995), where the trend and cycle components are orthogonal, but the trend component is generated from serially correlated errors. ${ }^{8}$

What is the relationship between the $\mathrm{BN}$ decomposition $\left(y_{t}^{g}\right.$ and $\left.y_{t}^{c}\right)$ and shocks identified by the recursive scheme $\left(\nu_{t}^{P}\right.$ and $\left.\nu_{t}^{T}\right)$ ? When there is an error correction term in (2.5), the bivariate cointegrated system generally implies that the random-walk trend component $y_{t}^{g}$ is generated by a linear combination of current $\nu_{t}^{P}$ and $\nu_{t}^{T}$. However, if we impose $\gamma_{c}=0$, the long-run impulse response to identified shocks becomes lower triangular, and thus the random-walk trend component $y_{t}^{g}$ is generated only from the permanent shock $\nu_{t}^{P}$. In contrast, the cyclical component $y_{t}^{c}$ consists of current and past values of both type of shocks, $\nu_{t}^{P}$ and $\nu_{t}^{T}$.

What does this imply about the relationship between our saving-based business cycle measure (2.1) and the ECM/BN cycle? ${ }^{9}$ Cochrane points out that, if consumption follows a pure random walk, as predicted by the simple permanent income model, the ECM/BN trend becomes $(\log )$ consumption less the mean of savings, $y_{t}^{g}=c_{t}-\bar{s}_{t}$. Thus the ECM/BN cycle is simply demeaned savings, $y_{t}^{c}=y_{t}-y_{t}^{g}=s_{t}-\bar{s}_{t}$. In the presence of a deterministic trend, the cyclical component becomes detrended savings, $y_{t}^{c}=s_{t}-\alpha-\beta t$, which corresponds to (2.1) with a choice of $\bar{c}_{t}^{g}=c_{t}$. What happens if consumption growth is serially correlated? Such an extension can be considered by imposing $\beta_{c 3}=\beta_{c 4}=0$ in (2.5). The Statistical Appendix shows that the ECM/BN cycle once again corresponds to (2.1) provided consumption is smoothed according to:

$$
\bar{c}_{t}^{g}=\sum_{i=0}^{2} w_{i} c_{t-i}
$$

where $w_{0}=\frac{1}{1-\left(\beta_{c 1}+\beta_{c 2}\right)}, w_{1}=\frac{-\beta_{c 1}}{1-\left(\beta_{c 1}+\beta_{c 2}\right)}$, and $w_{2}=\frac{-\beta_{c 2}}{1-\left(\beta_{c 1}+\beta_{c 2}\right)}$. It is important to note that the moving average weights, $w_{i}$ 's, depend only on the coefficients in (2.5), not on those in (2.6). It is straightforward to obtain a similar result for the more generalized case beyond

\footnotetext{
${ }^{8}$ See also Gonzalo and Ng (2001) for identification of shocks combined with Granger-Gonzalo decompostion, and Levtchenkova, Pagan and Robertson (1998) for a more comprehensive discussion.

${ }^{9}$ See Appendix A.2 for our definition of the BN cycle in a multivariate context. We adopt the opposite sign convention for the transitory component, making it procyclical.
} 
two lags in the ECM by adding more lags in the moving average of (2.7). In summary, even in the presence of transitory consumption variation, the ECM/BN cycle takes the form of (2.1) with the moving average weights for consumption determined by the parameters which capture the short-run dynamics of consumption growth.

\section{Estimation of ECMs in the G-7 and Australia}

The bivariate error-correction models of (2.5) and (2.6) are estimated on a country-bycountry basis. Quarterly series of GDP and total consumption are used for $Y_{t}$ and $C_{t}$, respectively. Both were obtained from the OECD database. The countries are: Australia, Canada, France, Italy, Germany, Japan, the United Kingdom, and the United States. The starting dates of the samples vary, all end in the first quarter of 2005 (see Table 1).

Table 1 reports the estimation results obtained using a restricted multivariate GLS method. The coefficient $\gamma_{y}$ on the error correction term is positive in all cases supporting the saving for a rainy day implication of Campbell (1987): when the representative consumer increases her consumption above income (dissaving) it foretells an increase in income growth. Furthermore, all the point estimates fall in the range of cointegrating restriction $\gamma_{y} \in(0,2)$ mostly with a tight confidence interval (exceptions are Italy and the United Kingdom). Thus, the results are consistent with long-run budget constraints.

In contrast, the short-run dynamics are imprecisely estimated: the coefficients on lagged consumption and income growth are statistically significant in only 18 of 56 cases. Fourteen of these statistically significant coefficients are accounted for by only three countries: Japan (6), Canada (4) and Italy (4). There is no tendency for lagged growth rates to be more significant in the consumption equation than in the income equation. In this sense, the cointegrating relationship is the robust feature of the empirical model.

\subsection{Decomposition of variance}

Table 2 reports variance decompositions at forecast horizons of one quarter, one year and infinity. As the Table shows, consumption changes are largely unpredictable, consistent with 
a random walk. As a consequence, virtually all of the variance in consumption growth gets attributed to the permanent shock. In sharp contrast, the variance of output growth is split almost exactly 50-50 between permanent and transitory shocks for the United States and this is robust across forecast horizons. Cochrane (1994) attributed $85 \%$ of the 1-quarter ahead forecast to the transitory component compared to only about $60 \%$ here. Most of this difference is likely due to the fact that his bivariate specification also included an errorcorrection term in (2.5), thereby allowing transitory shocks to alter the long-run level of consumption and income and elevating their importance in the variance decomposition of output. Germany and the United Kingdom are similar to the U.S. with about $60 \%$ of output variation attributed to the transitory shock. Japan is an outlier with a small fraction of variance attributed to the transitory shock (40\%). What is interesting about the remaining countries -Australia, Canada, France and Italy - is that transitory shocks are even more important than is true of the U.S.. Thus the international evidence against the pure random walk model of output growth seems even more compelling in other countries than it is for the United States.

\subsection{Impulse responses}

The estimated impulse responses, are broadly consistent with those produced using the model of King, Plosser and Rebelo (1988) presented earlier in Figure 1. The half-life of the income response to a transitory shock is 7 quarters according to the quantitative theory. The average half-life across countries using the estimated impulse responses (Figure 2) is very close to this, at 8 quarters. The path back to the steady-state is predicted to be monotonic in the benchmark theory, typical of our estimates. Consumption displays a hump-shape response rising for a number of quarters before returning monotonically back to the steady-state level. According to the theory, the hump-shaped response reflects the interaction of wealth and substitution effects. The wealth effect of a transitory shock is small as is evident from the fact that the theoretical impulse never exceeds 0.25 percent above the steady-state in response

to a persistent unit (1 percent) productivity shock. The initially high real interest rate, 
generated by higher productivity creates an upward sloping profile in the initial few quarters due to an intertemporal substitution effect.

Turning to the case of a pure random walk productivity shock (i.e. a permanent increase in productivity of $1 \%$ ), the basic neoclassical model predicts a monotonically rising profile of both consumption and income. Both variables increase toward new higher steady-state levels, with consumption everywhere below income. The reason for this is that in the new higher steady-state, the capital is higher than initially to re-equate the higher marginal product of capital (due to higher productivity) with the unchanged steady-state real interest rate. To accomplish this, investment must rise above the steady-state by more in the short-run than the long-run; this accounts for the gap in consumption and income along the transition path. In an open economy the tension between consumption and investment in the income identity is relaxed and as we shall see in the empirical results, consumption tends to track income more closely in the permanent shock case in open economies. Interestingly the largest countries look more like the closed economy simulation, consistent with the notion that the tension between consumption and investment again arises at the global level.

Figure 2 shows the impulse responses are quite similar across countries. Most countries display monotonic transitions of GDP back to the steady-state following a transitory disturbance. An exception is Japan, where output keeps rising for three quarters before adjustment back toward the steady-state begins. The half-life of the response of output in the neoclassical model is 8 quarters which is within one quarter of the empirical estimates for Australia, Canada, France and the United States. Germany has a much lower empirical half-life of 4 quarters while Japan, Italy and the United Kingdom have half-lives of 2 years or more. A significant fraction of the higher half-life for Japan is due to the hump-shaped output response; it takes 11 quarters for the impulse to return to its level at impact.

Turning to consumption, recall the impact response to a transitory shock is restricted to be zero in the empirical model. Some delay is evident in the maximal estimated consumption response, but not as much as the theory implies. The consumption profiles also display 
different sensitivity to the same magnitude disturbance across countries.

Permanent shocks carry the economy to a new higher level of consumption and income while restoring the ratio of these two key macroeconomic variables in both the theory and the estimated model. Most of the empirical impulses indicate rapid adjustment toward the new higher steady state with half of the adjustment achieved in the first few quarters. Only Australia, Italy and the United Kingdom take more than one year to account for one-half of the distance between the impact response and the new higher steady-state level of output. The response of the calibrated neoclassical model is considerably slower.

The simplest version of the permanent income hypothesis predicts that consumption rises in exact proportion to income if the shock is exogenous and permanent. This is what gives rise to the classic prediction that a permanent income shock has no implication for a nation's current account. Here, however, a permanent shock generates a predictable rise in income. In the neoclassical theory, this is because a permanent rise in productivity leads to a process of capital accumulation to a new higher steady-state, which takes real time to accomplish. Consumption, therefore is expected to rise above income initially based on permanent income logic, even in the permanent productivity shock case. Empirically, however, income moves almost immediately to its long-run level and therefore consumption and income move quite closely together, in response to the permanent shock. This contrasts strongly with the transitory shock case where most of the movements are in income, while consumption barely adjusts.

\section{Saving cycles and ECM/BN cycles}

\subsection{Summary statistics}

This section computes our saving-based business cycle measure for each nation and compares them with the BN cycle obtained from the restricted bivariate ECM estimates as well as some commonly used univariate business cycle measures. We denote Cochrane's ECM/BN cycle by $E C M-B N$. The simplest version of our saving-based measure, namely, the detrended 
savings with the choice of $\bar{c}_{t}^{g}=c_{t}$ in (2.1) is denoted by $S V$. The saving-based measure derived using a moving average of consumption $\bar{c}_{t}^{g}=(1 / 4) \sum_{j=0}^{4-1} c_{t-j}$, is denote by $S V-M A$. The saving-based measure with the HP-filtered consumption obtained by minimizing (2.3) with $\lambda=1600$ is denoted by $S V$-HP. The univariate BN business cycle measure obtained from the OLS estimate of a second-order autoregressive (AR) model of output growth is denoted by $B N$, and the standard HP cycle obtained by minimizing (2.2) with $\lambda=1600$ is denoted by $H P$.

Table 3 reports the standard deviations of the cyclical measures. The notable finding here is that the magnitude of volatility in general is much larger for the multivariate measures than for the univariate measures. For the multivariate measures, ECM-BN cycle and saving-based cycles, SV in particular, are remarkably similar to each other. For the univariate measures, the largest (across country) cyclical volatility for the BN cycle barely reaches a standard deviation of $0.5 \%$, the mean across countries is a mere $0.34 \%$. The small contribution of the $\mathrm{BN}$ cycle to the variance of output is the flipside of the argument, by Beveridge and Nelson (1981), that output is close to a random walk. The standard deviation of the HP cycle is always intermediate between the univariate BN model and the multivariate models. Moreover, cyclical variability of output according to the univariate BN model is trivial.

Table 4 examines the time series correlations of the various estimates of the cycle. The BN cycle has an average (across countries) correlation of near zero with multivariate measures, such as ECM-BN and SV. The HP cycle is positively correlated with multivariate measures for all countries, with the highest correlation being 0.72 with SV-HP. Based on the similarity of the moments of the ECM-BN cycle and the SV cycle, one might suspect that the two follow a similar time path. Figure 3, in fact, shows that the two estimates are virtually identical. Simply put: to a very close approximation, savings is the cycle in GDP and consumption is the trend.

The obvious difference between the HP cycle and the SV cycle (see Figure 3) is that the SV produces business cycles significantly longer in duration and greater in amplitude than 
the HP cycle (for the U.S., the two are more comparable). The average duration of these cycles would push the upper limits of what business cycle theorists (or the NBER dating committee, for that matter) would consider reasonable. And yet, if the goal of the exercise is to parse the data into trend and cycle for purposes of applications to growth theory and business cycle theory, it seems logical to infer the stochastic trend from permanent income behavior of the mythical representative agent rather than relegate the task to a purely statistical procedure.

Taking the view that non-inflationary or sustainable economic growth is tracked by the growth component, the implication of our cyclical measure is dramatically different from the conventional view of the output gap using the HP filter. The differences involve many policy relevant aspects: i) the extent of variance around the growth trend, ii) the duration of cycle; and iii) the timing of turning points. The welfare implications of business cycles is also altered given the greater persistence and volatility of the deviations from the growth path.

\subsection{The international comovement puzzle}

Given the analysis above, it should not be surprising that the simple saving-based measure of business cycles has dramatic implications for some key business cycle facts. Consider the most cited of these: the international correlation of GDP. The correlation of U.S. and foreign business cycles, is uniformly positive using the HP cycle, averaging about 0.5 across countries. This is higher than the correlation of 0.02 produced in the two-sector, two-country benchmark model of Backus, Kehoe and Kydland (1994). ${ }^{10}$ The contrast of the observed and simulated moments has been dubbed the comovement puzzle: pointing to the observation that models have difficulty producing the high international output correlations observed in the data. Table 5 shows that the SV measure of the cycle in U.S. output has an average correlation of nearly zero with its foreign counterpart. Aiming for this empirical target seems

\footnotetext{
${ }^{10}$ Baxter and Crucini (1995) explore the role of incomplete markets in a one-sector, two-country business cycle model and find significantly positive output correlations arise only when productivity are near random walks with modest international correlations in the innovations and no dynamic spillovers.
} 
likely to change the relative merit of alternative international business cycle models.

\subsection{The Great Moderation}

Stock and Watson (2005) documented a decline in the size of common, international, shocks in recent decades. In this sense business cycle volatility may be sensitive not only to the choice of the method of the trend-cycle decomposition but also to the time period. Table 6 shows the standard deviations of alternative business cycle measures computed for two subsamples. We follow Stock and Watson and divide the sample into a period that ends in 1993 and a period starting in 1994. On average, we observe declines in all the business cycle measures as we move from the first period to the second period. However, volatility reductions are not so obvious when multivariate measures are employed in place of univariate measures. In fact, standard deviations are actually larger in the second subsample when SV and SV-MA cycles are employed. It could be that better economic policy smoothed out high frequency variation while the underlying cycle perceived by consumers remained as volatile as ever.

\section{Conclusions}

As emphasized by Canova (1998), alternative detrending filters extract different types of business cycle information from the data. ${ }^{11}$ The standard approach to business cycle decompositions in macroeconomics is the univariate HP filter. Baxter and King (1999) and the NBER business cycle dating committee take nuanced approaches, starting with a formal definition of what a business cycle should look like in terms of duration or judging business cycle peaks and troughs using multiple indicators but not holding to an algorithm, respectively. Applying minimal theoretical restrictions embodied in traditional macroeconomic models, such as the permanent income model, we find that business cycles do not conform to these conventional approaches. Consequently, many of the empirical challenges in the

\footnotetext{
${ }^{11}$ Cogley and Nason (1995) go further and show that the Hodrick-Prescott filter can create periodicities in the cyclical component when none exist in the original series.
} 
business cycle literature may be different than was previously thought. Two key dimensions of business cycle facts found to be very sensitive to filtering relate to ongoing debates about the extent of international comovement and the Great Moderation. While obviously central to business cycle research, these two examples are just illustrative, there are likely other key relationships such as the association of nominal and real variables deserving of the same scrutiny. Much remains to be done. 


\section{Appendix}

\section{A1. Multivariate GLS Estimation of Restricted Vector ECMs}

An unrestricted bivariate ECM with lag two (with constant and trend term),

$$
\begin{aligned}
{\left[\begin{array}{l}
\Delta c_{t} \\
\Delta y_{t}
\end{array}\right]=} & {\left[\begin{array}{l}
\alpha_{c 1} \\
\alpha_{y 1}
\end{array}\right]+\left[\begin{array}{l}
\alpha_{c 2} \\
\alpha_{y 2}
\end{array}\right] t+\left[\begin{array}{l}
\gamma_{c} \\
\gamma_{y}
\end{array}\right]\left(c_{t-1}-y_{t-1}\right) } \\
& +\left[\begin{array}{ll}
\beta_{c 1} & \beta_{c 3} \\
\beta_{y 1} & \beta_{y 3}
\end{array}\right]\left[\begin{array}{l}
\Delta c_{t-1} \\
\Delta y_{t-1}
\end{array}\right]+\left[\begin{array}{ll}
\beta_{c 2} & \beta_{c 4} \\
\beta_{y 2} & \beta_{y 4}
\end{array}\right]\left[\begin{array}{c}
\Delta c_{t-2} \\
\Delta y_{t-2}
\end{array}\right]+\left[\begin{array}{c}
\varepsilon_{t}^{c} \\
\varepsilon_{t}^{y}
\end{array}\right]
\end{aligned}
$$

can be written in a matrix form

$$
\Delta X=A Z+E
$$

where $\Delta X=\left[\Delta X_{1}, \ldots, \Delta X_{T}\right], \Delta X_{t}=\left(\Delta c_{t}, \Delta y_{t}\right)^{\prime}, Z=\left[Z_{0}, \ldots, Z_{T-1}\right]$,

$$
\begin{gathered}
Z_{t}=\left[\begin{array}{l}
1 \\
t \\
c_{t-1}-y_{t-1} \\
\Delta X_{t-1} \\
\Delta X_{t-2}
\end{array}\right], \\
A=\left[\begin{array}{lllllll}
\alpha_{c 1} & \alpha_{c 2} & \gamma_{c} & \beta_{c 1} & \beta_{c 3} & \beta_{c 2} & \beta_{c 4} \\
\alpha_{y 1} & \alpha_{y 2} & \gamma_{y} & \beta_{y 1} & \beta_{y 3} & \beta_{y 2} & \beta_{y 4}
\end{array}\right]
\end{gathered}
$$

and $E=\left[\varepsilon_{1}, \ldots, \varepsilon_{T}\right]$. A linear restriction $\gamma_{c}=0$ on $A$ can be expressed by $a=\operatorname{vec}(A)=S r+s$, where $\operatorname{vec}(A)=\left(\alpha_{c 1}, \alpha_{y 1}, \alpha_{c 2}, \alpha_{y 2}, \gamma_{c}, \gamma_{y}, \beta_{c 1}, \beta_{y 1}, \beta_{c 3}, \beta_{y 3}, \beta_{c 2}, \beta_{y 2}, \beta_{c 4}, \beta_{y 4}\right)^{\prime}$,

$$
S=\left[\begin{array}{ll}
I_{4} & 0 \\
0 & 0 \\
0 & I_{9}
\end{array}\right],
$$

$r=\left(\alpha_{c 1}, \alpha_{y 1}, \alpha_{c 2}, \alpha_{y 2}, \gamma_{y}, \beta_{c 1}, \beta_{y 1}, \beta_{c 3}, \beta_{y 3}, \beta_{c 2}, \beta_{y 2}, \beta_{c 4}, \beta_{y 4}\right)^{\prime}$ and $s=0$. Since

$$
\operatorname{vec}(\Delta X)=\left(Z^{\prime} \otimes I_{K}\right) \operatorname{vec}(A)+\operatorname{vec}(E)=\left(Z^{\prime} \otimes I_{K}\right) S r+\operatorname{vec}(E),
$$

a restricted GLS estimator is given by

$$
\begin{aligned}
\widehat{a} & =\operatorname{vec}(\widehat{A})=S \widehat{r} \\
& =S\left[S^{\prime}\left(Z Z^{\prime} \otimes \Sigma_{\varepsilon}^{-1}\right) S\right]^{-1} S^{\prime}\left(Z \otimes \Sigma_{\varepsilon}^{-1}\right) \operatorname{vec}(\Delta X)
\end{aligned}
$$

with its limit distribution

$$
\sqrt{T}(\widehat{a}-a) \stackrel{d}{\rightarrow} N\left[0, S\left[S^{\prime}\left(Q \otimes \Sigma_{\varepsilon}^{-1}\right) S\right]^{-1} S^{\prime}\right]
$$

where $Q=\operatorname{plim} Z Z^{\prime} / T$. 


\section{A2. Bivariate Beveridge-Nelson Decomposition of Restricted Vec- tor ECMs}

To simplify the derivation, we omit constant and trend term without the loss of generality. Suppose a vector ECM

$$
\Delta X_{t}=\gamma \beta^{\prime} X_{t-1}+\sum_{i=1}^{p} B_{i} \Delta X_{t-i}+\varepsilon_{t}
$$

where $X_{t}$ is an $n \times 1$ vector of variables, $\beta$ is an $n \times r$ matrix representing cointegrating vectors, $\gamma$ is an $n \times r$ loading coefficients, $B_{i}$ 's are $n \times n$ coefficient matrices and $\varepsilon_{t}$ is an $n \times 1$ zero mean error vector. Its $\operatorname{VAR}(1)$ representation is given by

$$
W_{t}=A W_{t-1}+u_{t}
$$

where $W_{t}=\left[\Delta X_{t}^{\prime}, \ldots, \Delta X_{t-p+1}^{\prime}, \beta^{\prime} X_{t-1}\right], A$ is an $(n p+r) \times(n p+r)$ coefficient matrix and $u_{t}$ is an $(n p+r) \times 1$ error vector. A multivariate version of Beveridge and Nelson (1981) decomposition for the $i$-th element of $X_{t}$ yields its cyclical component given by

$$
\tilde{X}_{i t}^{c}=\lim _{k \rightarrow \infty} \sum_{j=1}^{k} e_{i}^{\prime} \widehat{W}_{t+j \mid t}=\lim _{k \rightarrow \infty} \sum_{j=1}^{k} e_{i}^{\prime} A^{j} W_{t}=e_{i}^{\prime} A(I-A)^{-1} W_{t}
$$

and trend component given by

$$
X_{i t}^{g}=X_{i t}+\tilde{X}_{i t}^{c}=X_{i t}+e_{i}^{\prime} A(I-A)^{-1} W_{t}
$$

where $e_{i}$ is a selection vector for $i$-th element. Note that we can simply flip the sign of the original BN cycle to much the definition of cyclical component in the main text as $X_{i t}^{c}=-\widetilde{X}_{i t}^{c}$. For a restricted bivariate ECM with transitory consumption $\left(\gamma_{c}=0\right.$ and $\left.\beta_{c 3}=\beta_{c 4}=0\right)$, its $\operatorname{VAR}(1)$ representation is simplified to

$$
\left[\begin{array}{l}
\Delta c_{t} \\
\Delta y_{t} \\
\Delta c_{t-1} \\
\Delta y_{t-1} \\
c_{t}-y_{t}
\end{array}\right]=\left[\begin{array}{lllll}
\beta_{c 1} & 0 & \beta_{c 2} & 0 & 0 \\
\beta_{y 1} & \beta_{y 3} & \beta_{y 2} & \beta_{y 4} & \gamma_{y} \\
1 & 0 & 0 & 0 & 0 \\
0 & 1 & 0 & 0 & 0 \\
\beta_{c 1}-\beta_{y 1} & -\beta_{y 3} & \beta_{c 2}-\beta_{y 2} & -\beta_{y 4} & -\gamma_{y}+1
\end{array}\right]\left[\begin{array}{l}
\Delta c_{t-1} \\
\Delta y_{t-1} \\
\Delta c_{t-2} \\
\Delta y_{t-2} \\
c_{t-1}-y_{t-1}
\end{array}\right]+\left[\begin{array}{l}
\varepsilon_{1 t} \\
\varepsilon_{2 t} \\
0 \\
0 \\
\varepsilon_{1 t}-\varepsilon_{2 t}
\end{array}\right] .
$$


Thus, for the transitory component of $y_{t}$, we have

$$
\begin{aligned}
& y_{t}^{c}=-\widetilde{y}_{t}^{c}=-\left[\begin{array}{lllll}
0 & 1 & 0 & 0 & 0
\end{array}\right] A(I-A)^{-1} W_{t} \\
& =-\left[\begin{array}{lllll}
0 & 1 & 0 & 0 & 0
\end{array}\right]\left[\begin{array}{lllll}
\beta_{c 1} & 0 & \beta_{c 2} & 0 & 0 \\
\beta_{y 1} & \beta_{y 3} & \beta_{y 2} & \beta_{y 4} & \gamma_{y} \\
1 & 0 & 0 & 0 & 0 \\
0 & 1 & 0 & 0 & 0 \\
\beta_{c 1}-\beta_{y 1} & -\beta_{y 3} & \beta_{c 2}-\beta_{y 2} & -\beta_{y 4} & -\gamma_{y}+1
\end{array}\right] \\
& \times\left[\begin{array}{lllll}
1-\beta_{c 1} & 0 & -\beta_{c 2} & 0 & 0 \\
-\beta_{y 1} & 1-\beta_{y 3} & -\beta_{y 2} & -\beta_{y 4} & -\gamma_{y} \\
-1 & 0 & 1 & 0 & 0 \\
0 & -1 & 0 & 1 & 0 \\
\beta_{y 1}-\beta_{c 1} & \beta_{y 3} & \beta_{y 2}-\beta_{c 2} & \beta_{y 4} & \gamma_{y}
\end{array}\right]^{-1}\left[\begin{array}{l}
\Delta c_{t} \\
\Delta y_{t} \\
\Delta c_{t-1} \\
\Delta y_{t-1} \\
c_{t}-y_{t}
\end{array}\right]
\end{aligned}
$$

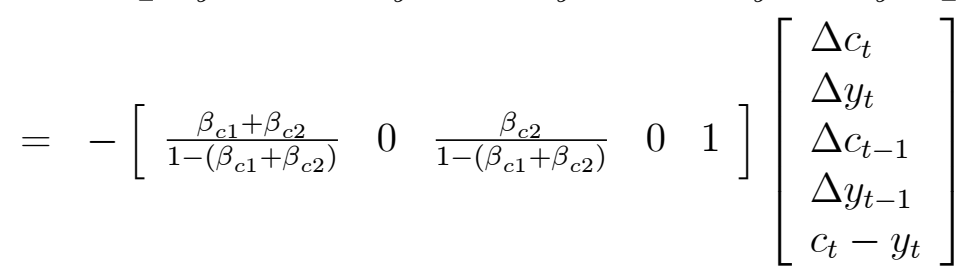

$$
\begin{aligned}
& =y_{t}-c_{t}-\frac{\beta_{c 1}+\beta_{c 2}}{1-\left(\beta_{c 1}+\beta_{c 2}\right)} \Delta c_{t}-\frac{\beta_{c 2}}{1-\left(\beta_{c 1}+\beta_{c 2}\right)} \Delta c_{t-1} \text {. }
\end{aligned}
$$

The trend component of $y_{t}$ can be obtained as

$$
\begin{aligned}
y_{t}^{g} & =y_{t}-y_{t}^{c}=y_{t}+c_{t}-y_{t}+\frac{\beta_{c 1}+\beta_{c 2}}{1-\left(\beta_{c 1}+\beta_{c 2}\right)} \Delta c_{t}+\frac{\beta_{c 2}}{1-\left(\beta_{c 1}+\beta_{c 2}\right)} \Delta c_{t-1} \\
& =\frac{1}{1-\left(\beta_{c 1}+\beta_{c 2}\right)} c_{t}+\frac{-\beta_{c 1}}{1-\left(\beta_{c 1}+\beta_{c 2}\right)} c_{t-1}+\frac{-\beta_{c 2}}{1-\left(\beta_{c 1}+\beta_{c 2}\right)} c_{t-2} .
\end{aligned}
$$

Consistent with the argument of Cochrane, in the case of random walk consumption with $\beta_{c 1}=\beta_{c 2}=0$, the results above implies that the cyclical component reduces to $y_{t}^{c}=y_{t}-c_{t}=$ $s_{t}$ (saving) and the trend component reduces to $y_{t}^{g}=c_{t}$ (consumption). 


\section{References}

[1] Backus, David K., Patrick J. Kehoe and Finn E. Kydland, 1994. Dynamics of the Trade Balance and the Terms of Trade: The J-Curve? American Economic Review 84(1), 84-103.

[2] Baxter, Marianne, and Mario J. Crucini, 1995. Business Cycles and the Asset Structure of Foreign Trade. International Economic Review 36(4), 821-854.

[3] Baxter, Marianne, and Robert G. King, 1999. Measuring Business Cycles: Approximate Band-Pass Filters For Economic Time Series. The Review of Economics and Statistics 81(4), 575-593.

[4] Beveridge, Stephen, and Charles R. Nelson, 1981. A New Approach to Decomposition of Economic Time Series into Permanent and Transitory Components with Particular Attention to Measurement of the Business Cycle. Journal of Monetary Economics 7, $151-174$.

[5] Blanchard, Olivier Jean, and Danny Quah, 1989. The Dynamic Effects of Aggregate Demand and Supply Disturbances. American Economic Review 79, 655-673.

[6] Campbell, John, Y., 1987. Does Saving Anticipate Declining labor Income? An Alternative Test of the Permanent Income Hypothesis. Econometrica 55(6) 1249-1273.

[7] Campbell, John Y., and Richard H. Clarida, 1987. Saving and Permanent Income in Canada and the United Kingdom, in Economic Effects of the Government Budget (E. Helpman, A. Razin, and E. Sadka, Eds.) 122-141, MIT Press, Cambridge, MA.

[8] Campbell, John Y., and Angus Deaton, 1989. Why Is Consumption So Smooth? Review of Economic Studies 56(3), 357-373.

[9] Canova, Fabio, 1998. Detrending and Business Cycle Facts, Journal of Monetary Economics 41, 475-512. 
[10] Cochrane, John H., 1994. Permanent and Transitory Components of GNP and Stock Prices. Quarterly Journal of Economics 30, 241-265.

[11] Cogley, Timothy, and James M. Nason, 1995. Effects of the Hodrick-Prescott Filter on Trend and Difference Stationary Time Series: Implications for Business Cycle Research. Journal of Economic Dynamics and Control 19(1-2), 253-278.

[12] Evans, George, and Lucrezia Reichlin, 1994. Information, Forecasts, and Measurement of the Business Cycle. Journal of Monetary Economics 33, 233-254.

[13] Gonzalo, Jesús and Clive Granger, 1995. Estimation of Common Long-Memory Components in Cointegrated Systems, Journal of Business \& Economic Statistics 13(1), 27-35.

[14] Gonzalo, Jesús and Serena Ng, 2001. A Systematic Framework for Analyzing the Dynamic Effects of Permanent and Transitory Shocks, Journal of Economic Dynamics and Control 25, 1527-1546.

[15] Hodrick, Robert J. and Edward C. Prescott, 1997. Postwar U.S. Business Cycles: An Empirical Investigation. Journal of Money, Credit and Banking 29(1), pages 1-16, February.

[16] King, Robert G., Charles I. Plosser and Sergio Rebelo, 1988. Production, Growth and Business Cycles I: The Basic Neoclassical Model. Journal of Monetary Economics 21, 195-232.

[17] King, Robert G., Charles I. Plosser, James H. Stock and Mark W. Watson, 1991, Stochastic Trends and Economic Fluctuations. American Economic Review 81, 819840.

[18] Lettau, Martin, and Sydney C. Ludvigson, 2004. Understanding Trend and Cycle in Asset Values: Reevaluating the Wealth Effect on Consumption. American Economic Review 94(1), 276-299. 
[19] Levtchenkova, S., A. R. Pagan and J. C. Robertson, 1998. Shocking Stories. Journal of Economic Surveys 12(5), 507-532.

[20] MacDonald, R., and C. Kearney, 1990. Consumption, Cointegration and Rational Expectations: Some Australian Evidence. Australian Economic Papers 29, 40-52.

[21] Morely, James C., 2007. The Slow Adjustment of Aggregate Consumption to Permanent Income. Journal of Money, Credit and Banking 39(2-3), 615-638.

[22] Morley, James C., Charles R. Nelson and Eric Zivot, 2003. Why Are the BeveridgeNelson and Unobserved-Components Decompositions of GDP so Different? Review of Economics and Statistics 85(2), 235-243.

[23] Ogaki, Masao, and Joon Y. Park, 1997. A Cointegration Approach to Estimating Preference Parameters. Journal of Econometrics 82, 107-134.

[24] Ravn, Morten O., 1997. Permanent and Transitory Shocks, and the UK Business Cycles, Journal of Applied Econometrics 12, 27-48.

[25] Rotemberg, Julio J., and Michael Woodford, 1996. Real-Business-Cycle Models and the Forecastable Movements in Output, Hours and Consumption, American Economic Review 86, 71-89.

[26] Shintani, Mototsugu, 1994. Cointegration and Tests of the Permanent Income Hypothesis: Japanese Evidence with International Comparisons. Journal of the Japanese and International Economies 8, 144-172.

[27] Stock, James H. and Mark W. Watson, 1988. Testing for Common Trends. Journal of the American Statistical Association 83, 1097-1107.

[28] Stock, James H. and Mark W. Watson, 2005. Understanding Changes in International Business Cycle Dynamics. Journal of the European Economic Association 3(5), 9681006. 
Table 1. - Bivariate Vector ECM Estimates

\begin{tabular}{lcccccccc}
\hline \hline Country & & const. & trend & $c_{t-1}-y_{t-1}$ & $\Delta c_{t-1}$ & $\Delta c_{t-2}$ & $\Delta y_{t-1}$ & $\Delta y_{t-2}$ \\
\hline Australia & & & & & & & & \\
& $\Delta c_{t}$ & 0.81 & 0.00 & 0.00 & 0.04 & 0.01 & 0.09 & 0.05 \\
1959:3 to 2005:1 & & $(5.24)$ & $(0.78)$ & $(-)$ & $(0.48)$ & $(0.13)$ & $(1.62)$ & $(0.94)$ \\
$\mathrm{T}=183$ & $\Delta y_{t}$ & 4.82 & 0.00 & 0.08 & 0.09 & 0.06 & -0.06 & 0.01 \\
& & $(2.44)$ & $(0.70)$ & $(1.91)$ & $(0.70)$ & $(0.47)$ & $(0.67)$ & $(0.15)$ \\
Canada & & & & & & & & \\
& $\Delta c_{t}$ & 0.90 & 0.00 & 0.00 & -0.19 & 0.03 & 0.29 & 0.05 \\
1961:1 to 2005:1 & & $(4.72)$ & $(1.67)$ & $(-)$ & $(2.17)$ & $(0.30)$ & $(3.21)$ & $(0.54)$ \\
$\mathrm{T}=177$ & $\Delta y_{t}$ & 6.02 & 0.00 & 0.10 & 0.15 & 0.19 & 0.18 & -0.05 \\
& & $(3.23)$ & $(0.19)$ & $(2.84)$ & $(1.66)$ & $(2.15)$ & $(1.97)$ & $(0.55)$ \\
France & & & & & & & & \\
& $\Delta c_{t}$ & 0.67 & 0.00 & 0.00 & -0.13 & 0.22 & -0.02 & 0.09 \\
1970:1 to 2005:1 & & $(3.84)$ & $(1.60)$ & $(-)$ & $(1.21)$ & $(2.17)$ & $(0.16)$ & $(0.64)$ \\
T =141 & $\Delta y_{t}$ & 3.18 & 0.00 & 0.05 & 0.11 & 0.15 & 0.12 & 0.13 \\
& & $(2.32)$ & $(0.32)$ & $(2.05)$ & $(1.45)$ & $(2.07)$ & $(1.07)$ & $(1.35)$ \\
Germany & & & & & & & & \\
& $\Delta c_{t}$ & 1.19 & -0.01 & 0.00 & -0.33 & -0.14 & 0.04 & 0.14 \\
1970:1 to 2005:1 & & $(5.17)$ & $(2.71)$ & $(-)$ & $(3.13)$ & $(1.36)$ & $(0.35)$ & $(1.24)$ \\
\multicolumn{1}{c}{$\mathrm{T}=141$} & $\Delta y_{t}$ & 9.04 & 0.00 & 0.15 & -0.14 & -0.05 & 0.07 & 0.13 \\
& & $(3.87)$ & $(2.11)$ & $(3.58)$ & $(1.46)$ & $(0.55)$ & $(0.61)$ & $(1.24)$ \\
\hline
\end{tabular}

Notes: The regressions are of the form:

$$
\begin{aligned}
\Delta c_{t}= & \alpha_{c 1}+\alpha_{c 2} t+\beta_{c 1} \Delta c_{t-1}+\beta_{c 2} \Delta c_{t-2}+\beta_{c 3} \Delta y_{t-1}+\beta_{c 4} \Delta y_{t-2}+\varepsilon_{t}^{c} \\
\Delta y_{t}= & \alpha_{y 1}+\alpha_{y 2} t+\gamma_{y}\left(c_{t-1}-y_{t-1}\right) \\
& +\beta_{y 1} \Delta c_{t-1}+\beta_{y 2} \Delta c_{t-2}+\beta_{y 3} \Delta y_{t-1}+\beta_{y 4} \Delta y_{t-2}+\varepsilon_{t}^{y}
\end{aligned}
$$

where $c_{t}=100 \times \ln C_{t}$ and $y_{t}=100 \times \ln Y_{t}$. Restricted multivariate generalized least squares estimates. 
Table 1 (continued). - Bivariate Vector ECM Estimates

\begin{tabular}{lcccccccc}
\hline \hline Country & & const. & trend & $c_{t-1}-y_{t-1}$ & $\Delta c_{t-1}$ & $\Delta c_{t-2}$ & $\Delta y_{t-1}$ & $\Delta y_{t-2}$ \\
\hline Italy & & & & & & & & \\
& $\Delta c_{t}$ & 0.40 & 0.00 & 0.00 & 0.42 & 0.16 & 0.14 & -0.08 \\
1970:1 to 2005:1 & & $(3.30)$ & $(1.98)$ & $(-)$ & $(4.56)$ & $(1.75)$ & $(2.27)$ & $(1.34)$ \\
$\mathrm{T}=141$ & $\Delta y_{t}$ & 7.83 & -0.01 & 0.13 & 0.31 & 0.15 & 0.30 & -0.05 \\
& & $(3.24)$ & $(3.09)$ & $(3.16)$ & $(2.20)$ & $(1.09)$ & $(3.17)$ & $(0.54)$ \\
Japan & & & & & & & & \\
& $\Delta c_{t}$ & 2.51 & -0.01 & 0.00 & -0.48 & -0.20 & 0.26 & 0.32 \\
1955:2 to 2005:1 & & $(7.72)$ & $(6.48)$ & $(-)$ & $(4.42)$ & $(1.80)$ & $(2.28)$ & $(2.77)$ \\
$\mathrm{T}=200$ & $\Delta y_{t}$ & 4.57 & -0.01 & 0.05 & -0.26 & -0.10 & 0.22 & 0.32 \\
& & $(4.21)$ & $(2.80)$ & $(2.45)$ & $(2.56)$ & $(0.98)$ & $(2.06)$ & $(2.96)$ \\
United Kingdom & & & & & & & & \\
& $\Delta c_{t}$ & 0.55 & 0.00 & 0.00 & -0.08 & 0.10 & -0.01 & 0.01 \\
1955:1 to 2005:1 & & $(3.09)$ & $(0.82)$ & $(-)$ & $(0.86)$ & $(1.06)$ & $(0.12)$ & $(0.06)$ \\
T =201 & $\Delta y_{t}$ & 2.27 & 0.00 & 0.03 & 0.11 & 0.11 & -0.14 & 0.02 \\
& & $(2.24)$ & $(1.32)$ & $(1.70)$ & $(1.31)$ & $(1.30)$ & $(1.58)$ & $(0.20)$ \\
United States & & & & & & & & \\
& $\Delta c_{t}$ & 0.60 & 0.00 & 0.00 & 0.12 & 0.10 & 0.10 & 0.01 \\
1955:1 to 2005:1 & & $(4.71)$ & $(0.17)$ & $(-)$ & $(1.30)$ & $(1.03)$ & $(1.41)$ & $(0.15)$ \\
\multicolumn{1}{c}{$\mathrm{T}=201$} & $\Delta y_{t}$ & 5.15 & -0.01 & 0.10 & 0.44 & 0.20 & 0.02 & 0.00 \\
& & $(3.20)$ & $(2.77)$ & $(3.06)$ & $(3.76)$ & $(1.62)$ & $(0.23)$ & $(0.05)$ \\
\hline
\end{tabular}


Table 2. - Consumption and Income Variance Decompositions

\begin{tabular}{|c|c|c|c|c|c|}
\hline \multicolumn{2}{|l|}{ Variance of: } & \multicolumn{2}{|c|}{$\Delta c_{t}$} & \multicolumn{2}{|c|}{$\Delta y_{t}$} \\
\hline \multirow[b]{2}{*}{ Country } & \multirow[b]{2}{*}{ Horizon } & \multicolumn{2}{|c|}{ Accounted for by } & \multicolumn{2}{|c|}{ Accounted for by } \\
\hline & & $\begin{array}{l}\text { Permanent } \\
\text { shocks }\end{array}$ & $\begin{array}{c}\text { Transitory } \\
\text { shocks }\end{array}$ & $\begin{array}{l}\text { Permanent } \\
\text { shocks }\end{array}$ & $\begin{array}{c}\text { Transitory } \\
\text { shocks }\end{array}$ \\
\hline \multirow[t]{3}{*}{ Australia } & 1 & 100.0 & 0.0 & 22.5 & 77.5 \\
\hline & 4 & 98.3 & 1.7 & 22.6 & 77.4 \\
\hline & $\infty$ & 98.2 & 1.8 & 22.3 & 77.7 \\
\hline \multirow[t]{3}{*}{ Canada } & 1 & 100.0 & 0.0 & 29.5 & 70.5 \\
\hline & 4 & 94.9 & 5.1 & 38.1 & 61.9 \\
\hline & $\infty$ & 94.6 & 5.4 & 37.2 & 62.8 \\
\hline \multirow[t]{3}{*}{ France } & 1 & 100.0 & 0.0 & 37.3 & 62.7 \\
\hline & 4 & 99.7 & 0.3 & 47.0 & 53.0 \\
\hline & $\infty$ & 99.7 & 0.3 & 46.8 & 53.2 \\
\hline \multirow[t]{3}{*}{ Germany } & 1 & 100.0 & 0.0 & 38.3 & 61.7 \\
\hline & 4 & 99.1 & 0.9 & 38.4 & 61.6 \\
\hline & $\infty$ & 99.1 & 0.9 & 37.5 & 62.5 \\
\hline \multirow[t]{3}{*}{ Italy } & 1 & 100.0 & 0.0 & 18.1 & 81.9 \\
\hline & 4 & 97.7 & 2.3 & 35.4 & 64.6 \\
\hline & $\infty$ & 97.6 & 2.4 & 36.1 & 63.9 \\
\hline \multirow[t]{3}{*}{ Japan } & 1 & 100.0 & 0.0 & 58.4 & 41.6 \\
\hline & 4 & 96.0 & 4.0 & 58.4 & 41.6 \\
\hline & $\infty$ & 95.7 & 4.3 & 57.3 & 42.7 \\
\hline United & 1 & 100.0 & 0.0 & 38.9 & 61.1 \\
\hline \multirow[t]{2}{*}{ Kingdom } & 4 & 100.0 & 0.0 & 39.2 & 60.8 \\
\hline & $\infty$ & 100.0 & 0.0 & 39.1 & 60.9 \\
\hline United & 1 & 100.0 & 0.0 & 41.2 & 58.8 \\
\hline \multirow[t]{2}{*}{ States } & 4 & 99.1 & 0.9 & 51.5 & 48.5 \\
\hline & $\infty$ & 99.0 & 1.0 & 50.8 & 49.2 \\
\hline
\end{tabular}

Note: See Table 1 for the sample period. 
Table 3. - Standard Deviations of Alternative Business Cycle Measures

\begin{tabular}{|c|c|c|c|c|c|c|}
\hline & \multicolumn{4}{|c|}{ Multivariate measures } & \multicolumn{2}{|c|}{ Univariate } \\
\hline & \multirow{2}{*}{$\begin{array}{c}\begin{array}{c}\text { Cochrane's } \\
\text { measure }\end{array} \\
\text { ECM-BN }\end{array}$} & \multicolumn{3}{|c|}{$\begin{array}{c}\text { Saving-based } \\
\text { measures }\end{array}$} & \multicolumn{2}{|c|}{ measures } \\
\hline & & SV & SV-MA & SV-HP & $\mathrm{BN}$ & HP \\
\hline Australia & 2.49 & 2.21 & 2.50 & 2.31 & 0.09 & 1.44 \\
\hline Canada & 2.15 & 1.57 & 1.77 & 1.85 & 0.34 & 1.39 \\
\hline France & 1.49 & 1.38 & 1.48 & 1.49 & 0.44 & 0.91 \\
\hline Germany & 1.73 & 1.58 & 1.59 & 1.77 & 0.07 & 1.34 \\
\hline Italy & 2.06 & 1.53 & 1.76 & 1.69 & 0.57 & 1.43 \\
\hline Japan & 3.22 & 2.15 & 2.34 & 2.54 & 0.52 & 1.50 \\
\hline United Ki & 3.30 & 3.31 & 3.30 & 3.37 & 0.10 & 1.45 \\
\hline United States & 1.69 & 1.40 & 1.60 & 1.94 & 0.55 & 1.55 \\
\hline Averages & 2.27 & 1.89 & 2.04 & 2.12 & 0.34 & 1.38 \\
\hline
\end{tabular}

Note: See Table 1 for the sample period. 
Table 4. - Correlation of Alternative Business Cycle Measures

\begin{tabular}{|c|c|c|c|c|c|c|}
\hline & \multicolumn{4}{|c|}{ Multivariate measures } & \multicolumn{2}{|c|}{ Univariate } \\
\hline & \multirow{2}{*}{$\begin{array}{c}\begin{array}{c}\text { Cochrane's } \\
\text { measure }\end{array} \\
\text { ECM-BN }\end{array}$} & \multicolumn{3}{|c|}{$\begin{array}{l}\text { Saving-based } \\
\text { measures }\end{array}$} & \multicolumn{2}{|c|}{ measures } \\
\hline & & SV & SV-MA & SV-HP & $\mathrm{BN}$ & HP \\
\hline \multicolumn{7}{|c|}{ (1) Correlation with ECM-BN } \\
\hline Australia & 1.00 & 1.00 & 0.94 & 0.87 & 0.27 & 0.49 \\
\hline Canada & 1.00 & 0.99 & 0.85 & 0.75 & -0.05 & 0.26 \\
\hline France & 1.00 & 0.99 & 0.83 & 0.76 & -0.03 & 0.23 \\
\hline Germany & 1.00 & 0.98 & 0.91 & 0.80 & -0.18 & 0.42 \\
\hline Italy & 1.00 & 0.83 & 0.50 & 0.43 & 0.14 & 0.07 \\
\hline Japan & 1.00 & 0.99 & 0.92 & 0.88 & -0.09 & 0.39 \\
\hline United Kingdom & 1.00 & 1.00 & 0.95 & 0.88 & 0.03 & 0.08 \\
\hline United States & 1.00 & 0.97 & 0.75 & 0.72 & 0.06 & 0.39 \\
\hline Averages & 1.00 & 0.97 & 0.83 & 0.76 & 0.02 & 0.29 \\
\hline \multicolumn{7}{|c|}{ (2) Correlation with SV } \\
\hline Australia & - & 1.00 & 0.95 & 0.89 & 0.34 & 0.51 \\
\hline Canada & - & 1.00 & 0.88 & 0.77 & -0.18 & 0.30 \\
\hline France & - & 1.00 & 0.90 & 0.81 & -0.16 & 0.25 \\
\hline Germany & - & 1.00 & 0.85 & 0.77 & -0.20 & 0.40 \\
\hline Italy & - & 1.00 & 0.90 & 0.66 & -0.24 & 0.22 \\
\hline Japan & - & 1.00 & 0.92 & 0.87 & -0.14 & 0.39 \\
\hline United Kingdom & - & 1.00 & 0.95 & 0.89 & 0.01 & 0.08 \\
\hline United States & - & 1.00 & 0.88 & 0.79 & -0.16 & 0.45 \\
\hline Averages & - & 1.00 & 0.90 & 0.81 & -0.09 & 0.33 \\
\hline \multicolumn{7}{|c|}{ (3) Correlation with HP } \\
\hline Australia & - & - & 0.58 & 0.74 & 0.39 & 1.00 \\
\hline Canada & - & - & 0.38 & 0.77 & -0.31 & 1.00 \\
\hline France & - & - & 0.29 & 0.66 & -0.34 & 1.00 \\
\hline Germany & - & - & 0.49 & 0.79 & -0.36 & 1.00 \\
\hline Italy & - & - & 0.36 & 0.79 & -0.30 & 1.00 \\
\hline Japan & - & - & 0.51 & 0.72 & -0.38 & 1.00 \\
\hline United Kingdom & - & - & 0.18 & 0.43 & -0.34 & 1.00 \\
\hline United States & - & - & 0.50 & 0.86 & -0.34 & 1.00 \\
\hline Averages & - & - & 0.41 & 0.72 & -0.25 & 1.00 \\
\hline
\end{tabular}

Note: See Table 1 for the sample period. 
Table 5. - International Business Cycle Comovement with the U.S.

\begin{tabular}{|c|c|c|c|c|c|c|}
\hline & \multicolumn{4}{|c|}{ Multivariate measures } & \multicolumn{2}{|c|}{ Univariate } \\
\hline & \multirow{2}{*}{$\begin{array}{c}\text { Cochrane's } \\
\text { measure } \\
\text { ECM-BN }\end{array}$} & \multicolumn{3}{|c|}{$\begin{array}{l}\text { Saving-based } \\
\text { measures }\end{array}$} & \multicolumn{2}{|c|}{ measures } \\
\hline & & SV & SV-MA & SV-HP & $\mathrm{BN}$ & $\mathrm{HP}$ \\
\hline Australia & 0.24 & 0.27 & 0.31 & 0.40 & -0.33 & 0.43 \\
\hline Canada & 0.01 & 0.00 & 0.06 & 0.45 & 0.57 & 0.72 \\
\hline France & 0.25 & 0.24 & 0.20 & 0.23 & 0.29 & 0.36 \\
\hline Germany & -0.05 & -0.06 & -0.09 & 0.15 & 0.17 & 0.43 \\
\hline Italy & -0.17 & -0.15 & -0.04 & 0.19 & 0.15 & 0.33 \\
\hline Japan & -0.04 & -0.04 & -0.07 & 0.15 & 0.30 & 0.40 \\
\hline United Kingdom & -0.10 & -0.11 & -0.04 & 0.20 & 0.34 & 0.65 \\
\hline United States & 1.00 & 1.00 & 1.00 & 1.00 & 1.00 & 1.00 \\
\hline Averages & 0.02 & 0.02 & 0.05 & 0.25 & 0.21 & 0.47 \\
\hline
\end{tabular}

Note: Sample period is 1970:Q4 to 2005:Q1. 
Table 6. - Standard Deviations of Alternative Business Cycle Measures: Subsamples

\begin{tabular}{|c|c|c|c|c|c|c|}
\hline & \multicolumn{4}{|c|}{ Multivariate measures } & \multirow{2}{*}{\multicolumn{2}{|c|}{$\begin{array}{c}\text { Univariate } \\
\text { measures }\end{array}$}} \\
\hline & \multirow{2}{*}{$\begin{array}{c}\text { Cochrane's } \\
\text { measure }\end{array}$} & \multicolumn{3}{|c|}{$\begin{array}{c}\text { Saving-based } \\
\text { measures }\end{array}$} & & \\
\hline & & SV & SV-MA & SV-HP & $\mathrm{BN}$ & $\mathrm{HP}$ \\
\hline \multicolumn{7}{|c|}{ (1) 1970Q4 - 2005Q1 } \\
\hline Australia & 2.57 & 2.27 & 2.55 & 2.24 & 0.08 & 1.34 \\
\hline Canada & 1.96 & 1.45 & 1.78 & 1.81 & 0.34 & 1.50 \\
\hline France & 1.48 & 1.37 & 1.48 & 1.50 & 0.44 & 0.91 \\
\hline Germany & 1.68 & 1.54 & 1.59 & 1.75 & 0.06 & 1.34 \\
\hline Italy & 2.05 & 1.52 & 1.76 & 1.68 & 0.58 & 1.43 \\
\hline Japan & 2.70 & 1.79 & 1.84 & 2.11 & 0.45 & 1.32 \\
\hline United Kingdom & 3.05 & 3.11 & 3.11 & 3.18 & 0.10 & 1.50 \\
\hline United States & 1.68 & 1.31 & 1.29 & 1.87 & 0.51 & 1.61 \\
\hline Averages & 2.15 & 1.80 & 1.93 & 2.02 & 0.32 & 1.37 \\
\hline \multicolumn{7}{|c|}{ (2) 1970Q4-1983Q4 } \\
\hline Australia & 3.36 & 2.97 & 3.28 & 2.77 & 0.11 & 1.68 \\
\hline Canada & 2.00 & 1.47 & 1.73 & 1.71 & 0.43 & 1.75 \\
\hline France & 1.61 & 1.44 & 1.53 & 1.49 & 0.51 & 0.97 \\
\hline Germany & 2.12 & 1.87 & 2.01 & 2.20 & 0.07 & 1.60 \\
\hline Italy & 1.86 & 1.34 & 1.81 & 2.08 & 0.78 & 2.05 \\
\hline Japan & 2.66 & 1.78 & 2.08 & 2.23 & 0.50 & 1.57 \\
\hline United Kingdom & 2.05 & 2.05 & 2.21 & 2.29 & 0.14 & 1.96 \\
\hline United States & 2.00 & 1.42 & 1.14 & 2.41 & 0.72 & 2.29 \\
\hline Averages & 2.21 & 1.79 & 1.97 & 2.15 & 0.41 & 1.74 \\
\hline \multicolumn{7}{|c|}{ (3) 1984Q1 - 2005Q1 } \\
\hline Australia & 1.63 & 1.44 & 1.68 & 1.65 & 0.05 & 1.08 \\
\hline Canada & 1.95 & 1.45 & 1.80 & 1.87 & 0.28 & 1.31 \\
\hline France & 1.40 & 1.34 & 1.45 & 1.49 & 0.40 & 0.87 \\
\hline Germany & 1.34 & 1.28 & 1.25 & 1.41 & 0.06 & 1.16 \\
\hline Italy & 2.13 & 1.61 & 1.71 & 1.35 & 0.40 & 0.87 \\
\hline Japan & 2.02 & 1.38 & 1.46 & 1.63 & 0.37 & 1.16 \\
\hline United Kingdom & 2.02 & 2.07 & 2.33 & 1.96 & 0.06 & 1.13 \\
\hline United States & 1.41 & 1.19 & 1.30 & 1.33 & 0.31 & 0.96 \\
\hline Averages & 1.74 & 1.47 & 1.62 & 1.59 & 0.24 & 1.07 \\
\hline
\end{tabular}


Figure 1. Impulse responses from King, Plosser and Rebelo Model

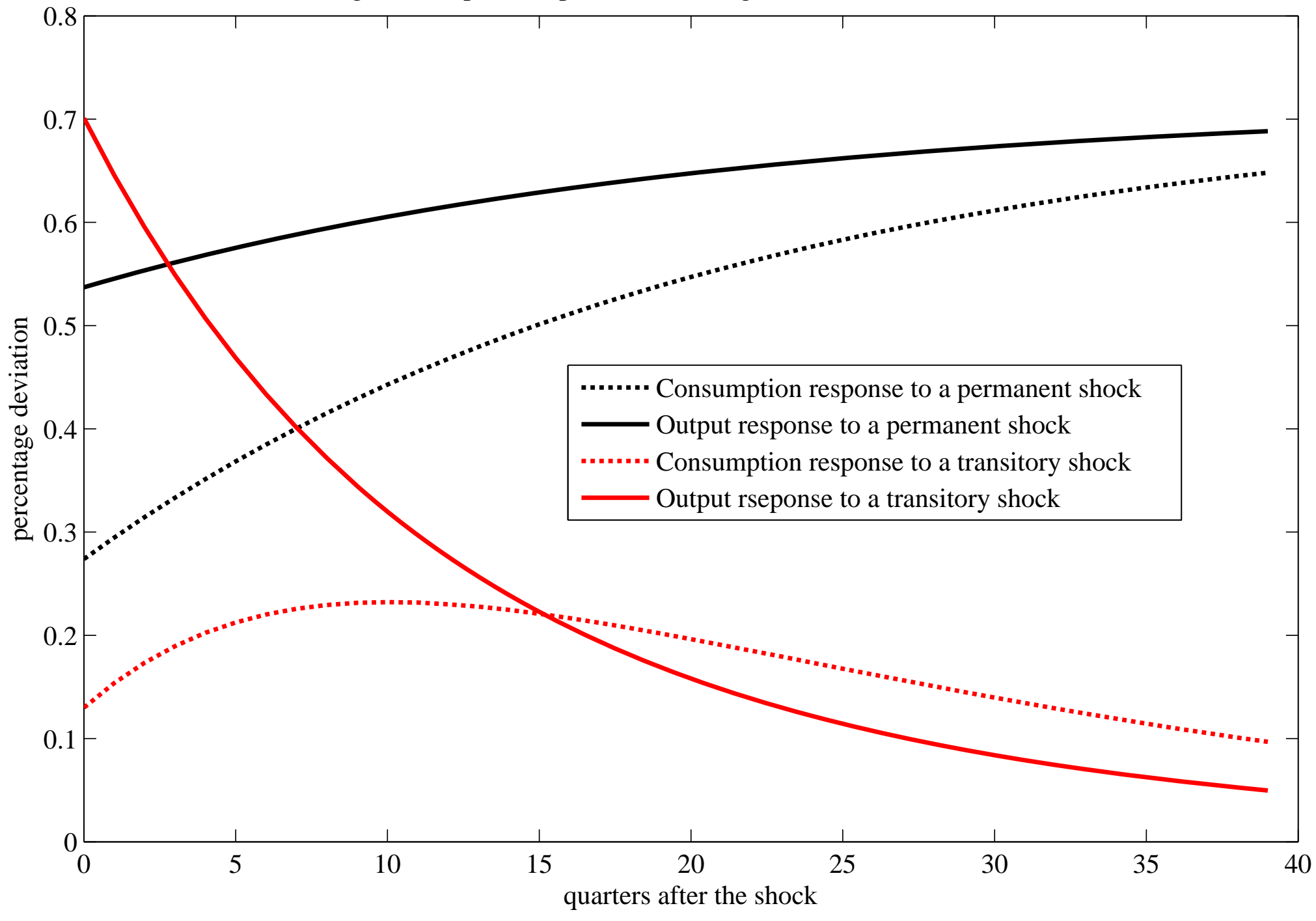


Figure 2. Impulse Response

Functions ECM/BM Model

Australia

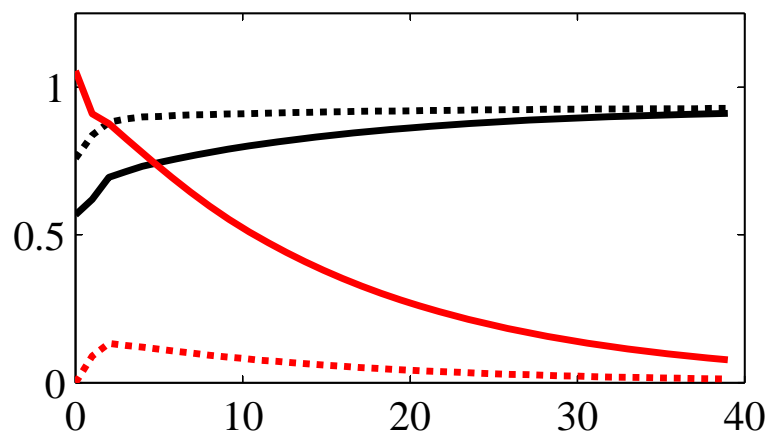

France

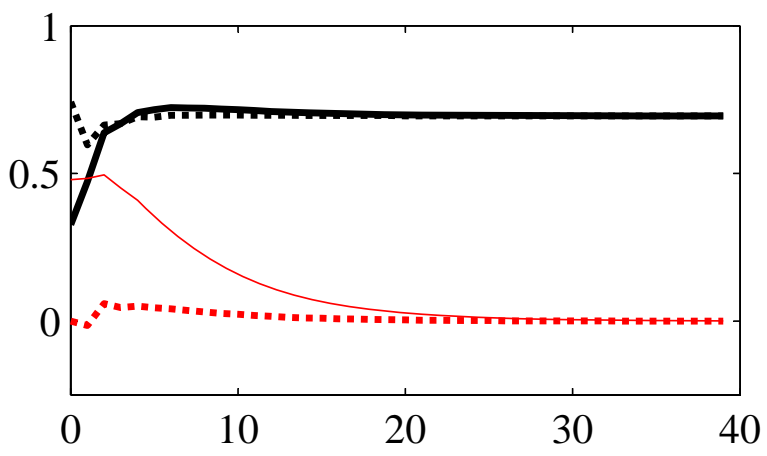

Italy

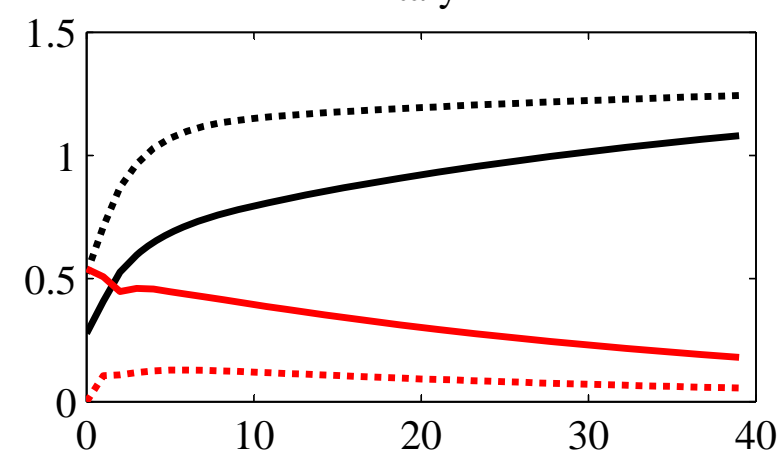

United Kingdom

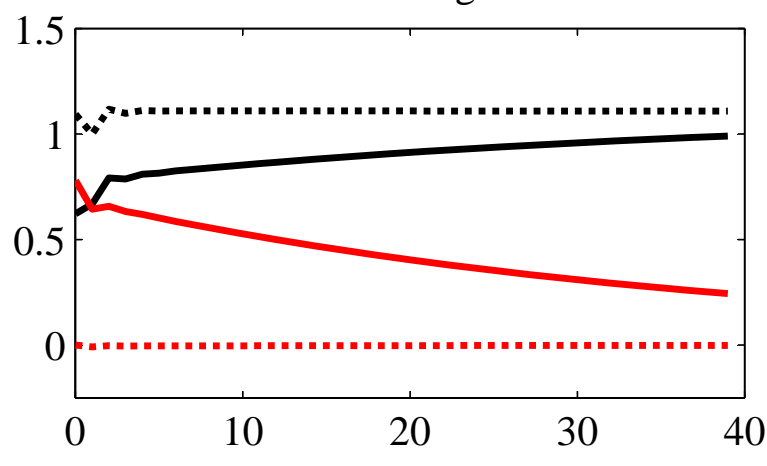

Canada

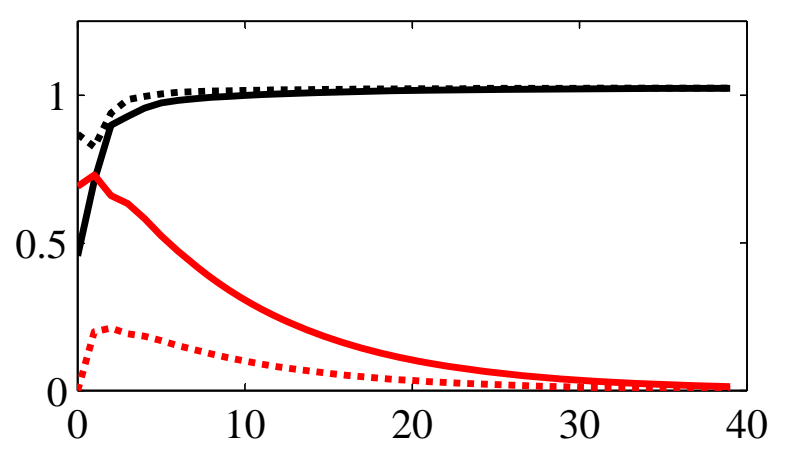

Germany

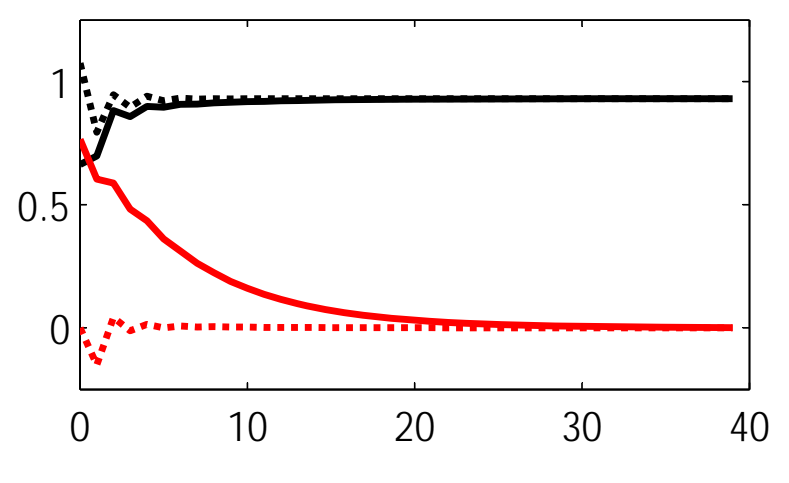

Japan

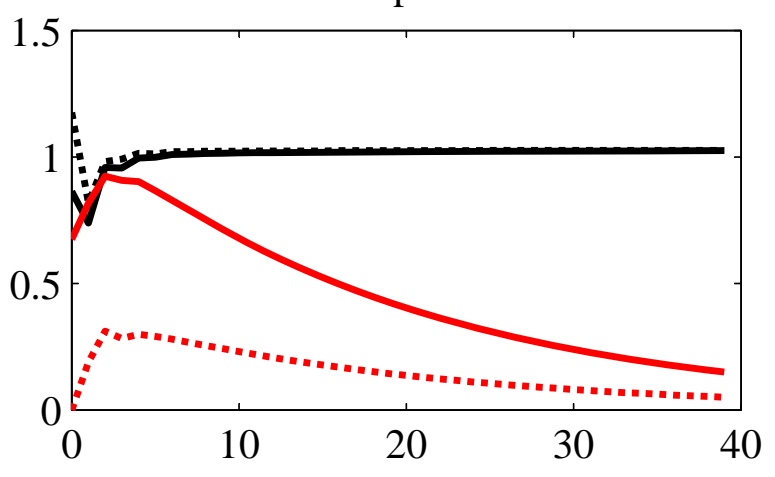

United States

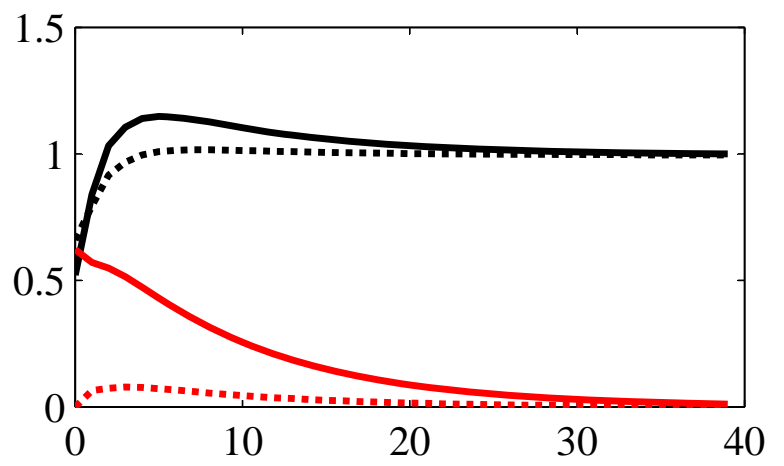


Figure 3. Business cycle estimates for select countries

Australia
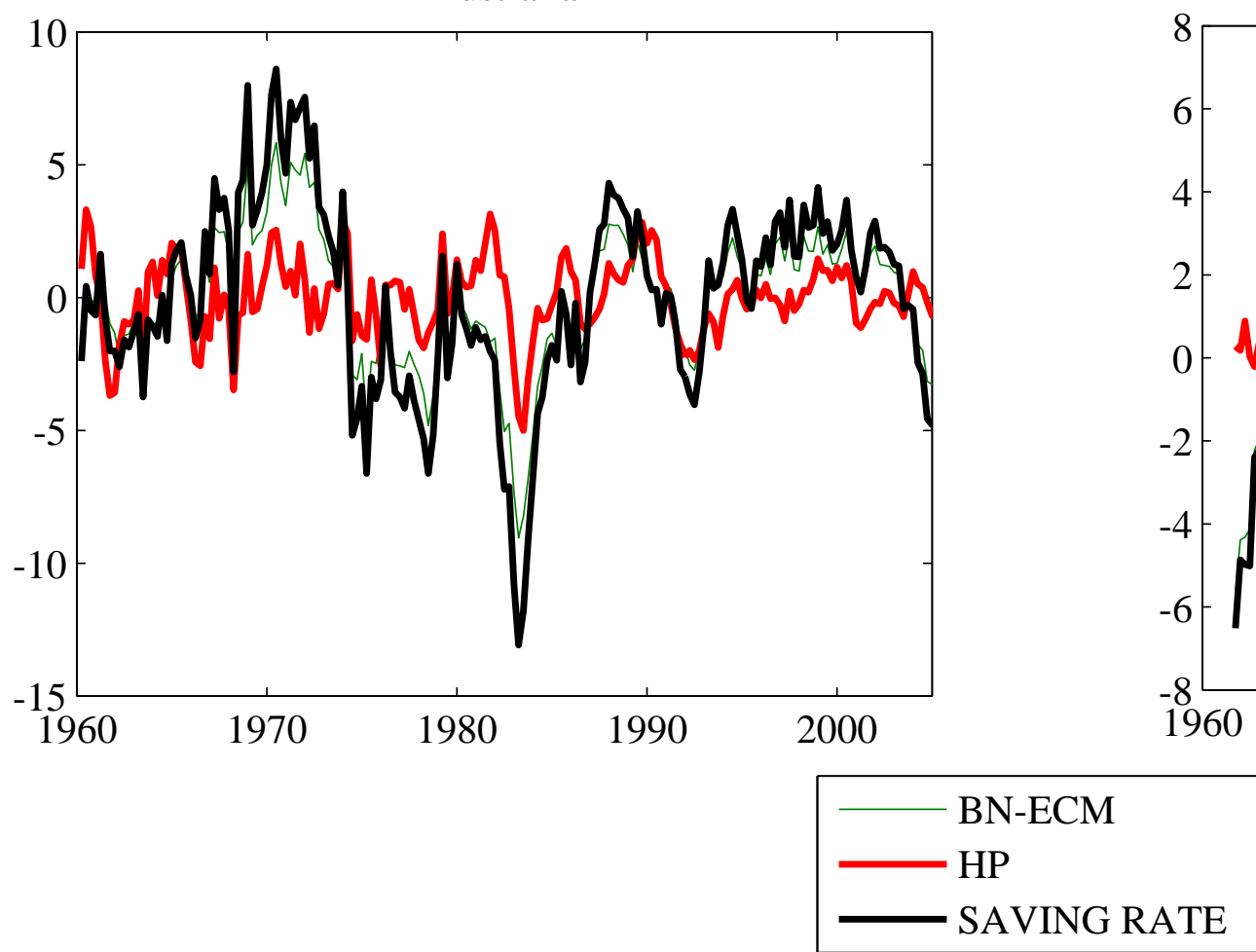

United Kingdom

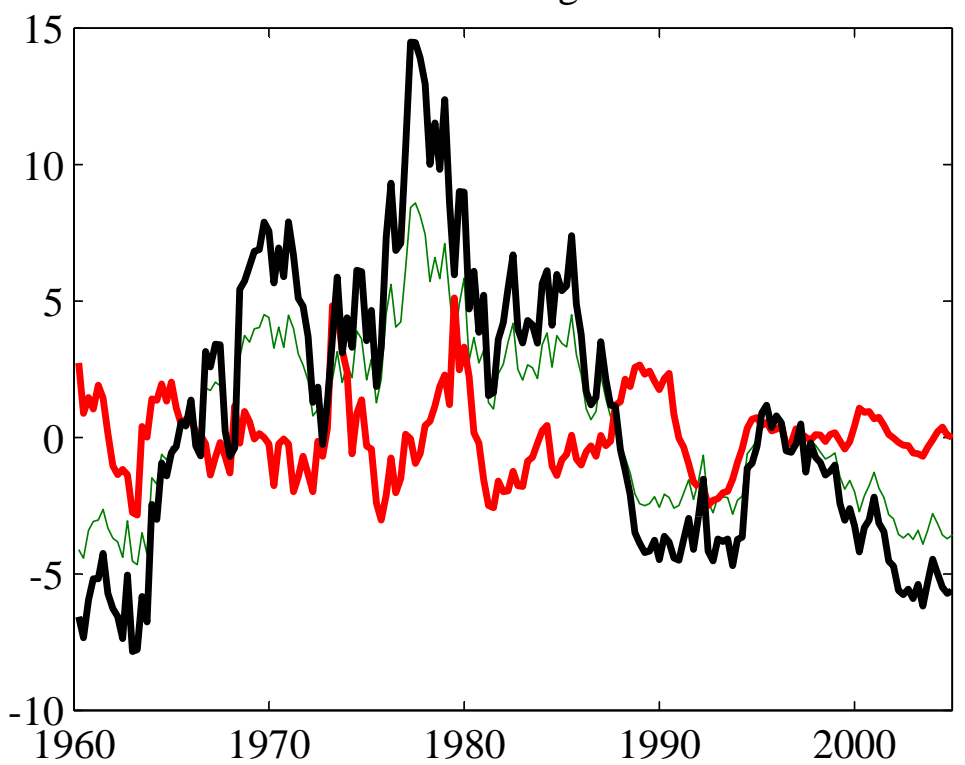

Canada

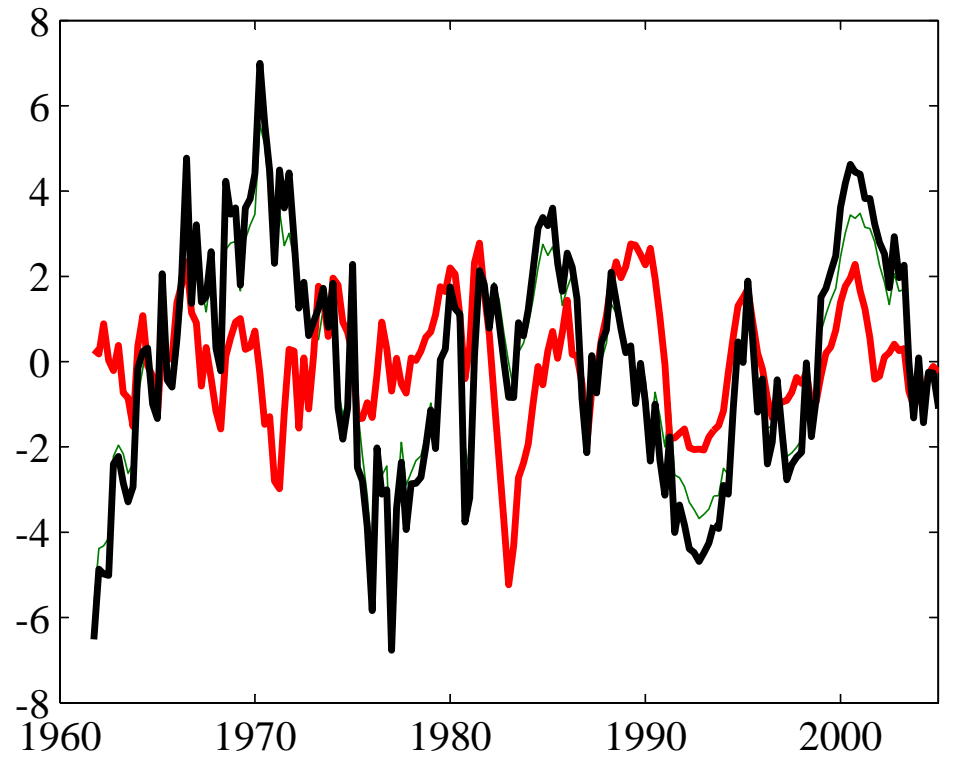

United States

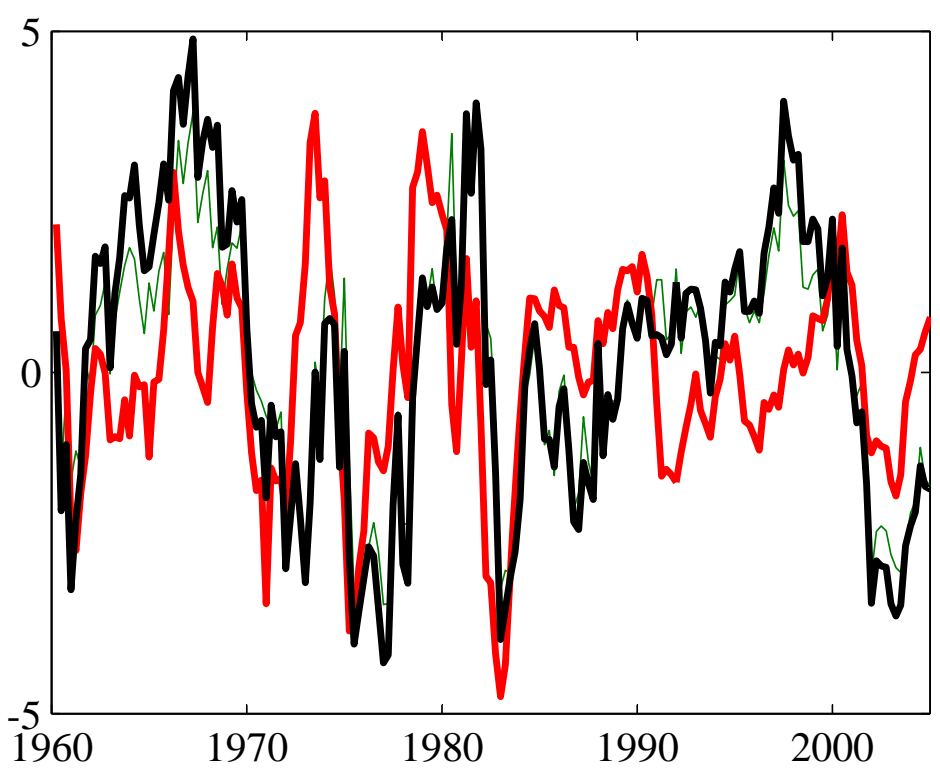

